\section{Psychiatry in pictures}

\section{CHOSEN BY ROBERT HOWARD}

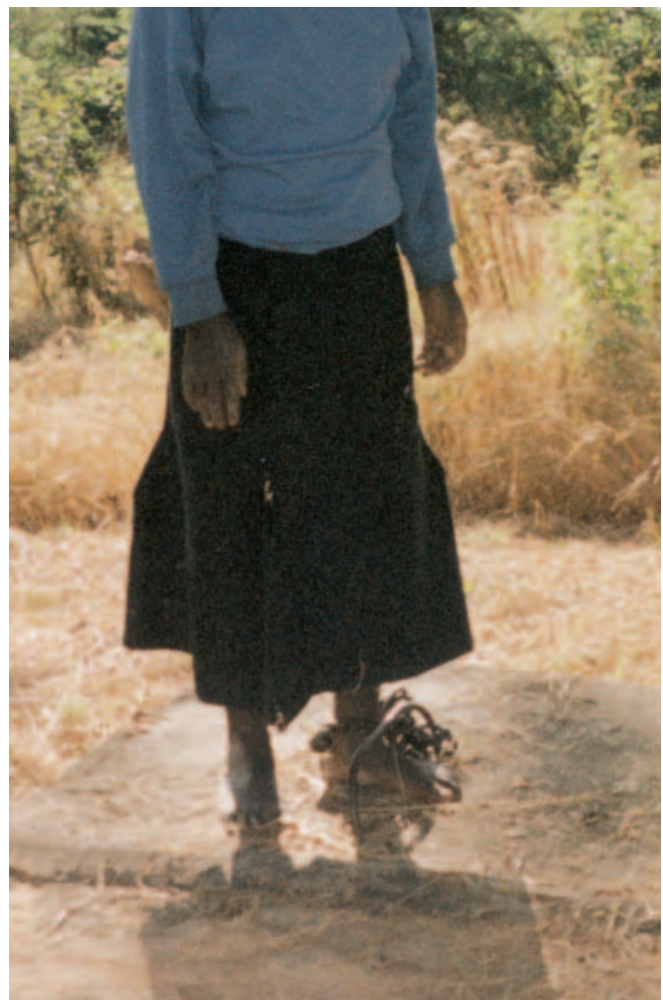

Do you have an image, preferably accompanied by 100 to 200 words of explanatory text, that you think would be suitable for Psychiatry in Pictures? Submissions are very welcome and should be sent direct to Professor Robert Howard, Box 070, Institute of Psychiatry, London SE5 8AF, UK.

Photograph of anonymous patient's feet taken May 1998 near Mozambique-Zimbabwe border

Dr Rene de Monchy, who is currently working as a registrar in psychiatry in Wellington, New Zealand, took these pictures while he was working as a doctor of tropical medicine in a mission hospital in Zimbabwe. 'I stopped the Landrover, not sure of whether what I saw was true. Here stood a woman, chained with irons to a block of concrete, under a tree. She was semimute ... only uttering incoherent and unintelligible sounds when I spoke to her in Shona. As I learned later from the people living not far off in the village, this woman was benzi, meaning crazy or mad, and a witch. Her family placed her there during the day and chained her in her hut at night'. After admission to the local mission hospital she disappeared the next day and was not seen again. 'Psychiatric illness, although present and often of an organic origin, is by necessity of low priority in those countries struggling to provide basic health care. Countries that are only hours flying away ... yet worlds apart in the concept and treatment of psychopathology. Perhaps it behoves us to contemplate the suffering and lack of help and resources befalling most of our fellow human beings in other parts of the world. In my case anyhow, this anonymous woman caused me to change my medical career of 25 years, general medicine, into the specialisation of psychiatry'. With thanks to Dr de Monchy for permission to reproduce his photographs.

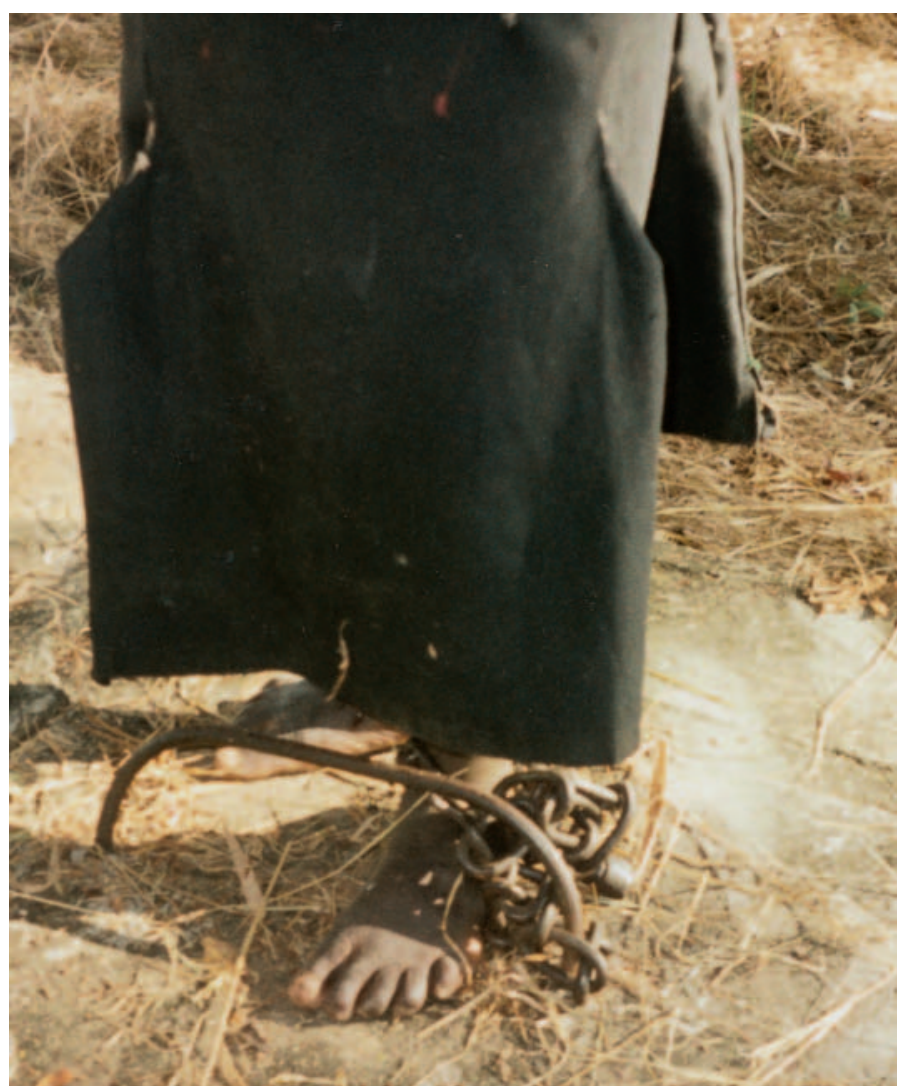

